\title{
CHALLENGES OF TEMPERATURE MEASUREMENT DURING THE FRICTION STIR WELDING PROCESS
}

\author{
Silke Augustin, Thomas Fröhlich, Gunter Krapf, Jean-Pierre Bergmann, Michael Grätzel, Jan Ansgar Gerken, Kiril \\ Schmidt \\ Technical University, Ilmenau, Germany, e-mail: silke.augustin@tu-ilmenau.de
}

\begin{abstract}
The exact determination of the process zone temperature can be considered as an increasingly important role in the control and monitoring of the friction stir welding process (FSW). At present, temperature measurement is carried out with the aid of a temperature sensor integrated into the tool (usually thermocouples). Since these cannot be attached directly to the joining area, heat dissipation within the tool and to the environment cause measurement deviations as well as a time delay in the temperature measurement. The article describes a process and the challenges that arise in this process, how a direct temperature measurement during the process can be achieved by exploiting the thermoelectric effect between tool and workpiece, without changing the tool by introducing additional temperature sensors.
\end{abstract}

\section{Keywords}

Friction stir welding, Direct temperature measurement, Seebeck-Effect, Measurement errors

\section{Introduction}

Friction Stir Welding (FSW) was developed and patented by Wayne Thomas at TWI (The Welding Institute) in Great Britain in 1991. It is assigned to the group of solid-state welding processes. In contrast to friction welding, the operating principle in FSW is not based on a relative movement of the workpieces, but by means of a wear-resistant rotating tool. One of the most relevant process variables is the axial force between the tool and the component. This force acts orthogonally to the welding direction and causes the tool to be completely immersed in and to remain in the joining area. This welding process is characterized by comparatively low joining temperatures below the melting temperature and excellent mechanical weld seam properties in comparison to conventional welding processes, such as arc and laser welding [1]. Friction stir welding is used in aerospace, shipbuilding, medical technology, and automotive engineering. However, the challenges for possible direct temperature measurement, based on the Seebeck effect, are the spindle speeds of the welding tool and the forces acting in the process. Thus, high demands on the design of the measuring device and the permanent transmission of the electrical voltage are necessary [2].

The measurement of the joining zone temperature during the process is an increasingly quantifiable indicator, as it allows conclusions to be drawn about the heat input and thus the thermomechanical stress on the microstructure [2-4]. Temperatures are currently measured by thermography or thermocouples, which are integrated into the welding tool [5]. However, the latter method is very costly and inaccurate, as the thermocouple does not contact the friction point between the shoulder of the tool and the workpiece. In addition, various publications have described that the thermocouples were either destroyed or changed in their position during the welding process so that an exact temperature measurement was not possible [3]. Measurement deviations and time delays can occur due to heat conduction in the tool or the heat transfer to the environment. An alternative to inserting thermocouples in the tool is the Tool-WorkpieceThermocouple method (TWT method), in which the occurring electrical thermoelectric voltage between tool and workpiece can be measured and then converted into a temperature value. However, this method places high demands on the used measuring circuits and the experimental determination of the various influencing parameters, as these have a decisive influence on the uncertainty of the measured temperature. In the following, the application of this method is described using the example of a robotized friction stir welding system and the results achieved are presented and discussed. 


\section{Fundamentals of Temperature Measurement with Thermocouples}

If there is a temperature difference $\mathrm{T}=\mathrm{T} 1-\mathrm{T} 2$ at the ends of a metallic conductor $(\mathrm{T} 1>\mathrm{T} 2)$, the electrons at the warm end are of higher thermal energy than the electrons at the cold end. As a result, the electron diffusion, which is the reason for the occurrence of a potential difference $\mathrm{E}$ along the conductor.

$$
E=\oint \frac{d U}{d T} \cdot \frac{d T}{d x} \cdot d x
$$

The quotient $\mathrm{d} U / \mathrm{d} T$, describing the occurring differential thermoelectric voltage $U$ along the conductor as a function of the temperature difference, is material-dependent and referred to as the Seebeck coefficient $\mathrm{S}(\mathrm{T})$ of the material.

The absolute thermoelectric emf of the conductor cannot be measured directly, but only indifference to the absolute thermoelectric emf of a conductor made of another material. This can be explained by the connecting wires of the voltmeter (mostly $\mathrm{Cu}$ ) that are led from the hot and cold end of the conductor through an unknown temperature field, thus generating further differential, unknown thermoelectric emf. Therefore, two electric conductors with known Seebeck coefficients are connected to form a thermocouple measuring circuit. The underlying physical principle, the Seebeck effect (Fig. 1), indicates that an electric current is generated in a loop of two different conductors A and B when different temperatures $T_{1}$ and $T_{2}$ are present at the junctions of the two conductors.

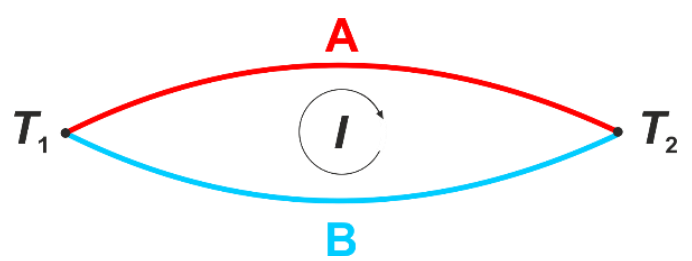

Fig. 1. Schematic representation of the Seebeck effect [6]

For measuring the resulting thermoelectric voltage, the closed circuit is disconnected at one point (Fig. 3) and a voltmeter is applied. In the most basic case, i.e. at low-temperature differences and for a homogeneous Seebeck coefficient for the entire conductor length, the following applies to the measured thermoelectric emf:

$$
U=\left(S_{A}-S_{B}\right) \cdot \Delta T
$$

The length and the cross-section of the respective conductors are not relevant in this case. It can also be assumed that inhomogeneous conductors, with constant Seebeck coefficients over the entire length of the conductor, the occurring thermoelectric voltage depends only on the temperature difference between the two junctions. Temperature gradients along the homogeneous conductors have no effect on the measured thermoelectric emf since the resulting differential partial voltages along the two conductors cancel each other. [6,7]. On the other hand, however, an additional thermoelectric voltage occurs when the Seebeck coefficient changes, e.g. due to mechanical or chemical influences on the conductor material, if these inhomogeneities in the conductor material are located in the temperature gradient $[8,9,10]$. For the basic circuit for temperature measurement with thermocouples, which is most frequently used in technology, the circuit is disconnected at a junction and the voltmeter is connected there via copper wires (Fig. 2). 


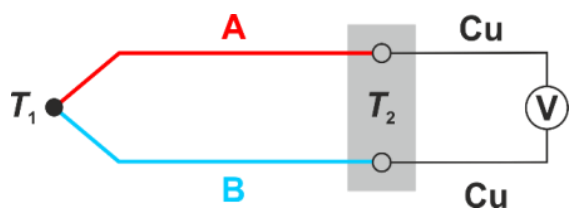

Fig. 2. Basic circuit of temperature measurement with thermocouples

The temperature $T_{2}$ must be known and constant over the measuring period. When defining their characteristic curve, internationally standardized thermocouples refer to a temperature $\mathrm{T}_{2}$, also known as reference junction temperature, of $\mathrm{T}_{\mathrm{V}}=0{ }^{\circ} \mathrm{C}$. If this reference junction temperature deviates from $0{ }^{\circ} \mathrm{C}$, a corresponding correction must be made when converting the thermoelectric voltage into temperature.

When it is not possible to lead the thermocouple cables to the cold junction, compensating or thermoelectric cables are used in practice. These cables provide the same thermoelectric material properties as the thermocouple cables used in a limited temperature range (up to approx. $200^{\circ} \mathrm{C}$ ). Ideally, no additional contributions to the thermoelectric emf should occur when using compensating cables, even if they are in the range of the temperature gradient. In practice, however, additional contributions to the measurement uncertainty occur, which must be considered in the measurement uncertainty budget.

The illustrated basic principle of temperature measurement with thermocouples can also be used for direct measurement of the temperature between tools and workpieces in production machines [6].

\section{Tool-Workpiece-Thermocouple (TWT-) Method}

In the present paper, the direct measurement of the electrical thermoelectric voltage between workpiece and tool is studied using the example of a robotic system for friction stir welding (Fig. 3). The average temperature is recorded along the entire contact surface between the tool and the workpiece.

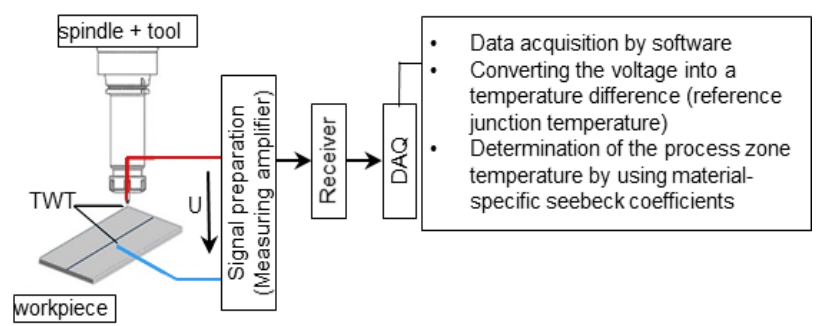

Fig. 3. Basic principle of the Tool-Workpiece-

Thermocouple (TWT) Method [11]

First, it is necessary to investigate which thermoelectric or compensating cables can be connected to the two basic elements of the electric thermoelectric voltage circuit in the welding robot so that a thermoelectric circuit up to the measuring device is created. It is to be expected that process-related temperature gradients will occur in the system, which could cause additional thermoelectric voltages with different material combinations. The Production Technology Group [11] has developed a grinding system for the test adaptable to the robotized FSW system (Fig. 4 above). The electrical 
voltage is to be tapped directly from the rotating tool and led to a thermoelectric cable. The grinding system is electronically isolated from the system in order to avoid interferences. The friction stir welding tool used consists of hardened tool steel (1.2344), and the workpieces to be joined are made of the aluminum alloy EN AW 6060 T66 with a sheet thickness of $5 \mathrm{~mm}$, a length of $300 \mathrm{~mm}$ and a width of $50 \mathrm{~mm}$. The workpieces were joined by butt joint formation. The individual components, which carry the thermoelectric voltage from the probe to the $\mathrm{Cu}$ cable, are made of the same material (1.2344) in order not to interfere with the rules for thermoelectric circuits.

For the following investigations, the friction stir welding tool or workpiece was first extended with thermoelectric cables made of the same materials as the tool and workpiece in order to tap the thermoelectric voltage. Copper cables were connected to these thermoelectric cables, comparable to the basic circuit in Fig. 2, to carry the signal to the measuring instrument (Fig. 4).

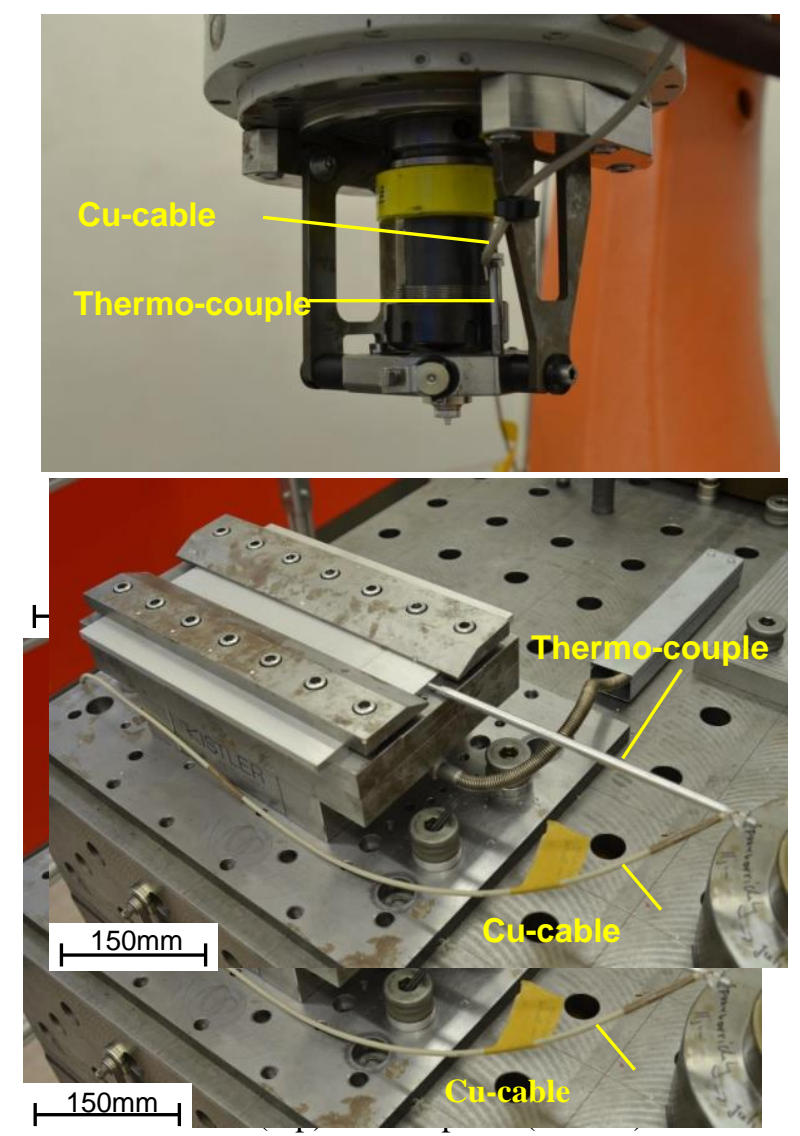

This design requires the reference point in the thermoelectric circuit to be located at different points in the system. It is not guaranteed that the reference junction temperature of both contact points is identical over the course of time. The heat dissipation through the thermoelectric lines was estimated in advance for heat conduction by analytical calculations and dimensioned in such a way that the same temperature finally prevails at the reference junctions. In the first measurements at the system, the temperature of the reference junctions was monitored by means of applied thermocouples to validate the previously calculated minimum lengths. The measurements confirmed the correctness of the assumptions made, the temperature at the reference junctions was the same.

\section{Results}

\subsection{Calibration of the material combination}

The used material combination of tool steel (1.2344) and aluminum alloy EN AW 6060 T66 does not belong to the internationally standardized thermocouple material combinations. Therefore, the T-U-characteristic or the Seebeck coefficient of the material pairing was determined at first. The calibration was carried out in a temperature-controlled 
test rig using a calibrated thermocouple. Figure 6 shows the results for the material combination 1.2344/EN AW 6060 T66.

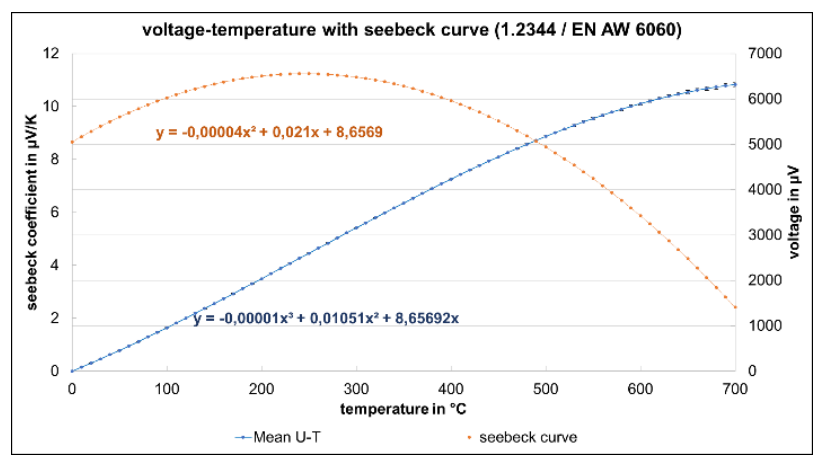

Fig. 5. Result of calibration for 1.2344 and EN AW 6060 [11]

The left ordinate axis shows the determined Seebeck coefficient (orange) and the opposite one the thermo-voltage axis (blue). The Seebeck coefficient was determined with the simplified equation 2. The temperature difference of the supporting points was $10 \mathrm{~K}$. The results were firstly used to calculate the temperatures during the welding process in order to prove the basic suitability of the measurement setup. The characteristic curve of the material combination is to be determined more precisely in subsequent tests in the calibration laboratory of the Institute for Process Measurement and Sensor Technology.

\subsection{Measurements at the robotized FSW welding unit}

The temperature measurement experiments are carried out on a serial kinematic 6-axis jointed-arm robot KUKA KR 500 MT 3. The robot is equipped with a modified FSW spindle from MAG, which is fitted with a tool clamping system for hollow shank tapers (HSK 63). The friction stir welding tool and workpiece were integrated into the system as described in chapter 3 . The resulting forces are recorded by a multi-component dynamometer from KISTLER, which is located below the component holder (Fig. 5).

The system was operated with the following welding parameters:

- welding speed: $1000 \mathrm{~mm} / \mathrm{min}$

- $\quad$ rotational speed: $5000 \mathrm{~min}-1$

- axial force: $4000 \mathrm{~N}$

- shoulder diameter: $13 \mathrm{~mm}$

- $\quad$ probe diameter: $5 \mathrm{~mm}$

- weld seam length: $250 \mathrm{~mm}$

- plunging depth: $4.5 \mathrm{~mm}$

For validation of the calculated temperatures from the Seebeck coefficients determined during calibration, sheath thermocouples type $\mathrm{K}$ were integrated into the center of the welding zone (stir zone). Therefore, grooves were prepared in the workpiece in which the thermocouples were inserted without damage (Fig. 6). The intention was to prove that the temperature in the welding zone measured with the system set up was almost on the same level as that of the thermocouples. The thermocouples were positioned $2 \mathrm{~mm}$ below the welding surface in the gap between the workpieces has to be joined. 


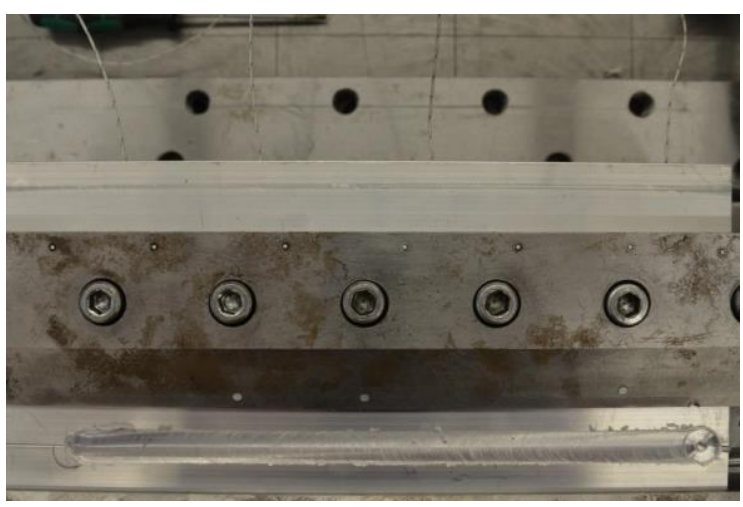

Fig. 6. Positioning of the thermocouples along the weld seam (from left TE1 - TE4)

The measured thermoelectric voltages were filtered with a passive low-pass filter of 1st order of $1 \mathrm{~Hz}$. Figure 8 shows the increase in temperature (red) and force (blue) of the material combination 1.2344 \& EN AW 6060 T66 throughout the welding time. It can be clearly noticed that the temperature rises during the plunging phase and reaches a maximum of $450{ }^{\circ} \mathrm{C}$ at appr. $12 \mathrm{~s}$. At the same time, a reduction of the axial force to almost $1000 \mathrm{~N}$ can be recognized, which is due to a reduction of the yield stress of the aluminum alloy. After the tool has sufficiently plasticized the workpiece material, the contact surface at which the electrical thermoelectric voltage is generated increases. Due to the contact with the still cool tool body and the plasticized workpiece, a temperature decrease of approx. $125^{\circ} \mathrm{C}$ can be determined. During the welding phase (starting at $\mathrm{t}=15 \mathrm{~s}$ ), the axial force $\left(4000 \mathrm{~N}\right.$ ) and the temperature (approx. $500{ }^{\circ} \mathrm{C}$ ) remain almost constant. The latter criterion corresponds to approx. 75\% of the liquidus temperature of EN AW $6060 \mathrm{~T} 66$. Immediately before the tool retraction, the force and the temperature rise briefly before the welding tool leaves the joining area. This can be explained by a short dwell time before the tool retraction whereby process-related reorientations of the spindle take place. The temperature curves of the thermocouples (TE1 - TE4) also shown in Figure 7, which should be used to validate the results of the direct thermoelectric voltage measurement (referred to as Tweld_ThermV in the diagram), always indicate a maximum below the temperature curves. This can be attributed both to a positioning slightly below the surface [7] and to the delay periods of the thermocouples. It was determined after the measurement that thermocouple 3 was not positioned exactly, which can be used to justify the deviating temperature curve.

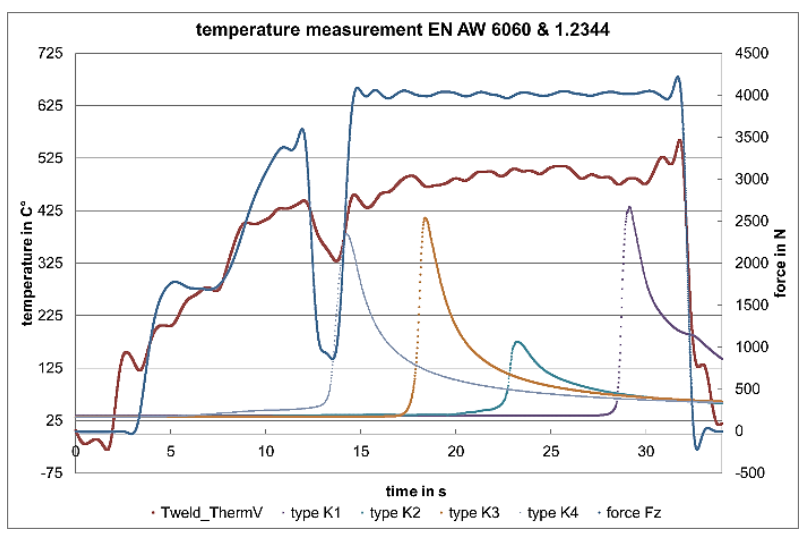

Fig. 7. Results during the welding process [11]

It is also noticeable that interference signals are already recorded before and also after welding, i.e. during the open thermoelectric circuit. This is mainly explained by disturbance variables, e.g. the $50 \mathrm{~Hz}$ mains frequency (correctable with low-pass filter), the rotational frequency of the rotating spindle or the system-related EMC load. As a result, both 
the values of the calibration and the results obtained during the welding process must be validated by repeat measurements.

\section{Summary and outlook}

The measurement results presented in the paper demonstrated that a direct temperature measurement can be accomplished using the TWT method. The calibration characteristic curve was determined for the material combination used and applied to measure the process zone temperature during the joining process. The achieved measuring values of the calibration should be additionally confirmed by an exact laboratory calibration. During the first measurements on the robotic FSW welding robot, the following influences on the measurement results and their uncertainty were identified:

- uncertainty of the characteristic curve determination,

- EMC load due to system periphery,

- wear of the probe during the welding process,

- not yet identified temperature gradients in the area of material transitions, which cause additional thermoelectric voltages.

In the future cooperation between the Production Technology Group and the Institute for Process Measurement and Sensor Technology at the TU Ilmenau, the possibilities of direct temperature measurement based on the Seebeck effect both for friction stir welding and for other welding processes are to be further investigated and verified. The heat transfer processes are also to be calculated in advance using numerical simulations [12] and subsequently verified by measurement technology.

\section{Conflict of Interest}

The authors claim that there are no possible financial or other conflicts over the work.

\section{References}

[1] D. Schmid: Reibrührschweißen von Aluminiumlegierungen mit Stählen für die Automobilindustrie, Dissertation, TU München, Herbert Utz Verlag GmbH, 2015.

[2] A. Fehrenbacher, C. Smith, N. Duffie, N. Ferrier, F. Pferfferkorn, M. Zinn: Combined Temperature and Force Control for Robotic Friction Stir Welding, ASME, J. Manuf. Sci. Eng 136(2), 021007 (Jan 15, 2014), Paper No: MANU-12-1357;

DOI: $10.1115 / 1.4025912$.

[3] A.C.F. Silva, J. De Backer, G. Bolmsjö: Temperature measurements during friction stir welding, University West, Trollhättan, Sweden, Springerlink.com, 2016.

DOI 10.1007/s00170-016-9007-4.

[4] E. Cole, A. Fehrenbacher, N. Duffie, M. Zinn, F. Pfefferkorn, N. Ferrier: Weld temperature effects during friction stir welding of dissimilar aluminum alloys 6061-t6 and 7075-t6, Int J Adv Manuf Technol (2014) 71:643-652.

DOI 10.1007/s00170-013-5485-9.

[5] A. Fehrenbacher, N. Duffie, N. Ferrier, F. Pfefferkorn, M. Zinn: Effects of tool-workpiece interface temperature on weld quality and quality improvements through temperature control in friction stir welding, The Int. Journ. Adv. Manuf. Techn., vol. 71, pp. 165-179, 2014/03/01, 2014.

[6] F. Bernhard (Hrsg.): Handbuch der Technischen Temperaturmessung, 2. Auflage, Springer-Verlag, 2014.

[7] M. Javurek, A. Mittermair: Wo in einem Thermoelement herrscht die gemessene Temperatur? Analyse mittels FESimulation, Technisches Messen, Heft 11, 2016, De Gruyter Oldenbourg.

DOI 10.1515/teme-2016-0028.

[8] P. Germanow: Messtechnische Untersuchung der Kennlinienstabilität von Thermoelementen, TU Ilmenau, Masterarbeit, 2019.

[9] E.S. Webster: Low-Temperature Drift in MIMS Base-MetalThermocouples, Springer Verlag, Int J Thermophys (2014) 35:574-595.

DOI 10.1007/s10765-014-1581-9.

[10] A.D. Greenen, E.S. Webster: Thermal Recovery from Cold-Working in Type K Bare-Wire Thermocouples, Springer Verlag, Int J Thermophys (2017) 38:179.

DOI 10.1007/s10765-017-2316-5.

[11] M. Baranowski, K. Schmidt, M.K. Stobrawa: Anwendung des Seebeck-Effekts zur Messung der Prozesszonentemperatur beim Reibrührschweißen, Dokumentation Projektseminar, TU Ilmenau, 2018. 
[12] M. Z. H. Khandkar, J. A. Khan, A. P. Reynolds: Prediction of temperature distribution and thermal history during friction stir welding: input torque based model, Sc. and Techn. of Welding \& Joining, 8(3):165-174, 2003.

DOI: $10.1179 / 136217103225010943$. 
